\title{
Characteristics of a Population of Women with Breast Implants Compared with Women Seeking Other Types of Plastic Surgery
}

\author{
Louise A. Brinton, Ph.D., S. Lori Brown, Ph.D., M.P.H., Theodore Colton, Sc.D., Mary Cay Burich, M.A., \\ and Jay Lubin, Ph.D. \\ Bethesda and Rockville, Md., Boston, Mass., and Chicago, Ill.
}

\begin{abstract}
Several previous studies have shown that breast implant patients demonstrate a number of differences compared with the general population. However, studies have not compared patients with breast implants with women receiving other types of plastic surgery, of interest because this latter group has been proposed as a comparison group for assessing the long-term health effects experienced by breast implant patients. Questionnaire data obtained from 7447 breast implant patients and 2203 patients with other types plastic surgery were collected during the course of a retrospective cohort study, to determine whether implant patients demonstrate different characteristics compared with a more restricted group of patients. In contrast to previous investigations that compared implant patients with the general population, distinctive differences with respect to family income, number of pregnancies, alcohol consumption, cigarette smoking, or histories of previous gynecologic operations or operations for benign breast disease were not found. However, implant patients were significantly more likely than other plastic surgery patients to be white, have low levels of education, have early ages at first birth, be thin, and be screened frequently for breast disease. Furthermore, implant patients reported somewhat greater use of exogenous hormones and familial histories of rheumatoid arthritis. These results support the notion that other plastic surgery patients are a more appropriate comparison group than women in the general population for studies of the health effects of breast implants; however, there continue to be distinctive characteristics possessed by breast implant patients, which need to be taken into account in an assessment of what disease effects can be uniquely attributed to silicone breast implants. (Plast. Reconstr. Surg. 105: 919, 2000.)
\end{abstract}

There is substantial interest in the adverse health effects of long-term exposure to silicone breast implants. Although numerous studies have assessed risk of cancer and various connective tissue diseases, most have had limited information on the characteristics of the women who seek implants. To interpret accurately the disease experience of implant patients, it is important to evaluate other factors that might independently affect disease risk.

A recent study compared selected characteristics of women who have breast implants with women in the general population and found several differences between the two groups, including greater proportions of implant patients who had their children early in life, had one or more induced abortions, used oral contraceptives, dyed their hair, drank alcoholic beverages, and had multiple sexual partners. ${ }^{1}$ As pointed out elsewhere, ${ }^{2}$ the study was limited in its inclusion of only a relatively small number of women with breast implants $(n=$ 80). In the present study, we evaluated the characteristics of a much larger group of women with breast implants. In addition, we could compare their characteristics with those of a group of women who had sought other types of plastic surgery, a group that has been suggested as a possibly more appropriate comparison group for breast implant patients than the general population. ${ }^{3}$ Thus, it was of interest to determine whether differences previously observed when implant patients were compared with the general population persisted when comparisons were made with a more restricted group of study patients. Through our

From the Environmental Epidemiology Branch, National Cancer Institute; Office of Surveillance and Biometrics, Center for Devices and Radiological Health, Food and Drug Administration; Department of Epidemiology and Biostatistics, Boston University School of Public Health; Abt Associates, Inc.; and Biostatistics Branch, National Cancer Institute. Received for publication February 25, 1999 ; revised June 23 , 1999. 
analyses, we attempted to identify characteristics of implant patients and to assess the appropriateness of use of other plastic surgery patients as a comparison group.

\section{Methods}

This analysis is a retrospective cohort study of the long-term health effects of silicone breast implants. We identified patients from 18 plastic surgery practices in six geographic areas (Atlanta, Georgia; Birmingham, Alabama; Charlotte, North Carolina; Miami and Orlando, Florida; and Washington, D.C.). We chose these practices on the basis of their having performed large numbers of silicone gel breast implant surgeries before 1989 and their willingness to give us unrestricted access to their records for purposes of identification and medical records abstraction. All female patients who had a first bilateral augmentation mammaplasty at these practices before 1989 were eligible. A total of 13,488 patients were identified. In all but one practice, we also attempted, after identification of approximately every fourth eligible breast implant patient, to identify a similarly aged comparison patient who had some other type of plastic surgery (not involving silicone) during the same time period. We identified a total of 3936 comparison patients, some of whom had multiple types of plastic surgery. Therefore, we categorized them into four categories, with priority given to the following order of operations (based primarily on expected extent of differences in terms of characteristics): (1) abdominoplasty or liposuction (20.5 percent); (2) blepharoplasty or rhytidectomy (34.2 percent) (operations for removal of wrinkles of the face and neck); (3) rhinoplasty; otoplasty, mentoplasty, genioplasty (28.1 percent) (operations involving the nose, ear, or chin); and (4) all other types of operations (17.2 percent).

Trained medical records abstractors reviewed medical records for eligibility and abstracted onto laptop computers patient identifiers and details on the types of surgery (including, if a breast implant patient, the implant type, manufacturer, and catalog number), any noted complications, and other factors that might affect health status (e.g., weight).

We sought vital status and residency information by means of a variety of tracing sources, including telephone directories, credit bureaus, driver's license bureaus, postmasters, and the National Death Index. We successfully traced 13,992 of the women (80.3 percent), including 364 women identified as deceased. The proportion of patients successfully traced was similar for implant (79.9 percent) and comparison (81.6 percent) patients. We mailed questionnaires to all living, located patients to obtain information on demographic factors, subsequent plastic surgeries, health status, and other personal characteristics. These other factors included menstrual, pregnancy, and breast-feeding history; use of exogenous hormones; anthropometric factors; cigarette smoking; alcohol consumption; breast screening history; and family history of selected diseases. Nonrespondents to several mailings were telephoned and given the opportunity to complete their interviews by telephone. The response rates for patients from whom questionnaires were sought were similar for the implant and other plastic surgery patients. Thus, we obtained completed questionnaires from 7447 (70.7 percent) of the traced implant patients and 2203 (71.1 percent) of the traced patients with other types of plastic surgery.

By using questionnaire data, we compared percentages of levels of characteristics between the breast implant and other plastic surgery patients. These percentages were directly adjusted to the joint population of all study patients to account for differences in ages at study enrollment. This method allowed for a comparison of characteristics unencumbered by age differences between the two groups. We also calculated odds ratios (OR) and 95 percent confidence intervals (CI) for various characteristics of interest, as a measure of comparison between the two groups. An odds ratio of 1.0 indicates no association between a characteristic and being a breast implant or a control patient. An odds ratio of 2.0 indicates that a characteristic has twice the odds of occurrence among breast implant patients, whereas an odds ratio of 0.5 indicates that the breast implant patients have half the odds. Given the large number of ratios calculated, they might have statistically differed from one by chance alone. Thus, 95 percent confidence intervals around the odds ratios were calculated to provide a measure of the certainty in the observed associations. In instances in which the confidence intervals excluded 1.0, there is a 95 percent or greater assurance that the true association differs from the null (i.e., no association). Logistic regression analyses were 
used to control for effects of age at and year of initial plastic surgery and to derive maximal likelihood estimates of adjusted odds ratios and their 95 percent confidence intervals. ${ }^{4}$

\section{RESULTS}

Table I presents descriptive information regarding the study groups. Implant patients were younger at the time of their surgery compared with the other plastic surgery patients (means of 33.2 versus 40.1 years). This finding primarily was attributable to more of the comparison patients having operations after the age of 45 years. More of the comparison patients had surgeries in the later years (1982 or later), reflecting to some extent the fact that controls were not included from one large practice with many early breast implant operations. Because of the differences between the implant and comparison women with respect to age and year of surgery, in our examination of other characteristics, we adjusted the odds ratios for these two variables.

We found that implant patients differed from the other plastic surgery patients in several demographic characteristics (Table II). After adjustment for age and year of surgery, less of the implant patients were nonwhite $(\mathrm{OR}=$ 0.81 ; 95 percent CI, 0.6 to 1.1 ) or had never been married ( $\mathrm{OR}=0.28 ; 95$ percent CI, 0.2 to $0.4)$. Furthermore, implant patients were less likely to have advanced degrees (odds ratio for completing college or beyond compared with a high school education or less $=0.52$; 95 percent CI, 0.5 to 0.6 ). Family income was unrelated to the occurrence of breast implants.

Table III shows findings for menstrual, re-

TABLE I

Description of the Study Population of Women

\begin{tabular}{|c|c|c|c|c|}
\hline \multirow[b]{2}{*}{ Parameter } & \multicolumn{2}{|c|}{$\begin{array}{c}\text { Breast Implant } \\
\text { Patients } \\
(n=7447)\end{array}$} & \multicolumn{2}{|c|}{$\begin{array}{c}\text { Other Plastic } \\
\text { Surgery Patients } \\
\quad(n=2203)\end{array}$} \\
\hline & $n$ & $\%$ & $n$ & $\%$ \\
\hline \multicolumn{5}{|c|}{ Age at initial plastic surgery (years) } \\
\hline$<25$ & 837 & 11.2 & 228 & 10.3 \\
\hline $25-29$ & 1639 & 22.0 & 189 & 8.6 \\
\hline $30-34$ & 2046 & 27.5 & 276 & 12.5 \\
\hline $35-39$ & 1519 & 20.4 & 318 & 14.4 \\
\hline $40-44$ & 809 & 10.9 & 339 & 15.4 \\
\hline $45+$ & 597 & 8.0 & 853 & 38.7 \\
\hline \multicolumn{5}{|c|}{ Calendar year of initial plastic surgery } \\
\hline$<1976$ & 835 & 11.2 & 156 & 7.1 \\
\hline $1976-1978$ & 1153 & 15.5 & 211 & 9.6 \\
\hline 1979-1981 & 1525 & 20.5 & 365 & 16.6 \\
\hline 1982-1984 & 1609 & 21.6 & 560 & 25.4 \\
\hline $1985+$ & 2325 & 31.2 & 911 & 41.4 \\
\hline
\end{tabular}

productive, and hormonal relationships. Implant patients were more likely to have later ages at menarche, have borne children, have more pregnancies, and have earlier ages at first birth. In addition, they significantly more often reported usage of either oral contraceptives $(\mathrm{OR}=1.5 ; 95$ percent $\mathrm{CI}, 1.3$ to 1.7$)$ or hormone replacement therapy $(\mathrm{OR}=1.2 ; 95$ percent CI, 1.0 to 1.3 ). However, when more detailed measures of hormone use were examined (e.g., years of use, age at first use), there was no further increase in the observed risks. The relationships shown in Table III were largely independent of each other, although the association with number of pregnancies disappeared after adjustment for age at first birth.

The majority of both implant and other plastic surgery patients classified their current health as being good to excellent. However, 9.4 percent of all patients reported their health as fair or poor, with the proportion being larger among the implant than comparison patients. Compared with patients who reported their health as excellent, odds ratios were 1.4 (95 percent CI, 1.1 to 1.7$)$ for fair health and 2.1 (95 percent CI, 1.5 to 3.1) for poor health.

In terms of other parameters of health $(\mathrm{Ta}-$ ble IV), significantly greater proportions of implant patients reported having had a mammogram $(\mathrm{OR}=2.1 ; 95$ percent $\mathrm{CI}, 1.8$ to 2.5$)$. This difference persisted even when consideration was given to mammograms performed at least 2 years before the initial plastic surgery $(\mathrm{OR}=2.2$; 95 percent $\mathrm{CI}, 1.8$ to 2.8$)$. In addition, breast implant patients were somewhat more likely to practice regular breast selfexaminations $(\mathrm{OR}=1.2$; 95 percent $\mathrm{CI}, 1.0$ to 1.4). Similar proportions of the two groups reported a prior breast biopsy, hysterectomy, or oophorectomy. In addition, there was no difference between the two groups with respect to frequency of recent Pap smears.

Implant patients reported that they weighed significantly less than the other plastic surgery patients $(\mathrm{OR}=0.63 ; 95$ percent $\mathrm{CI}, 0.5$ to 0.7 for current weights of $68+$ versus $<56 \mathrm{~kg}$ ) and that they were taller $(\mathrm{OR}=1.4 ; 95$ percent $\mathrm{CI}$, 1.2 to 1.7 for heights of $170+$ versus $<160 \mathrm{~cm}$ ) (Table V). Consequently, implant patients had significantly lower body mass indices than the comparison patients $(\mathrm{OR}=0.48 ; 95$ percent CI, 0.4 to 0.6 for body mass indices of $24.5+$ versus <20.5). Implant and comparison patients did not differ with respect to their con- 
TABLE II

Comparison of Breast Implant Patients and Other Plastic Surgery Patients on Demographic Characteristics

\begin{tabular}{|c|c|c|c|c|}
\hline Parameter & $\begin{array}{l}\% \text { of Breast Implant } \\
\text { Patients }(n=7447)\end{array}$ & $\begin{array}{c}\% \text { of Other Plastic } \\
\text { Surgery Patients } \\
(n=2203)\end{array}$ & $\begin{array}{l}\text { Adjusted } \\
\text { Odds Ratio* }\end{array}$ & $\begin{array}{c}95 \% \\
\text { Confidence } \\
\text { Interval }\end{array}$ \\
\hline \multicolumn{5}{|l|}{ Race } \\
\hline White & $97.3+$ & $96.3 \dagger$ & 1.00 & \\
\hline Nonwhite & 2.2 & 3.1 & 0.81 & $0.6-1.1$ \\
\hline Unknown & 0.5 & 0.6 & 0.98 & $0.5-2.1$ \\
\hline \multicolumn{5}{|l|}{ Marital status } \\
\hline Married, common-law & 62.7 & 56.1 & 1.00 & \\
\hline Separated, divorced & 17.9 & 16.1 & 1.00 & $0.9-1.2$ \\
\hline Widowed & 8.0 & 9.7 & 0.71 & $0.6-0.9$ \\
\hline Never married & 4.1 & 10.5 & 0.28 & $0.2-0.4$ \\
\hline Unknown & 7.3 & 7.6 & 0.85 & $0.7-1.0$ \\
\hline \multicolumn{5}{|l|}{ Education } \\
\hline High school or less & 31.9 & 21.8 & 1.00 & \\
\hline Some college & 33.9 & 30.3 & 0.76 & $0.7-0.9$ \\
\hline College or greater & 33.7 & 47.4 & 0.52 & $0.5-0.6$ \\
\hline Unknown & 0.4 & 0.5 & 0.40 & $0.2-0.9$ \\
\hline \multicolumn{5}{|l|}{ Income $(\$)$} \\
\hline$<35,000$ & 21.8 & 17.8 & 1.00 & \\
\hline $35,000-\$ 49,999$ & 13.4 & 13.9 & 0.85 & $0.7-1.0$ \\
\hline $50,000-\$ 69,999$ & 13.4 & 15.9 & 0.77 & $0.6-0.9$ \\
\hline $70,000-\$ 89,999$ & 9.9 & 10.8 & 0.88 & $0.7-1.1$ \\
\hline $90,000+$ & 24.6 & 24.8 & 0.93 & $0.8-1.1$ \\
\hline Unknown & 16.9 & 16.7 & 0.90 & $0.8-1.1$ \\
\hline
\end{tabular}

* Adjusted for age at and year of initial plastic surgery.

$\dagger$ Age-adjusted frequencies.

sumption of alcoholic beverages (consumption at least once a month or more) or smoking histories (ever smoked cigarettes). There were no substantial differences between the implant and comparison patients even when we considered more detailed measures of alcohol consumption or cigarette smoking.

We also inquired about first-degree family histories of several diseases among the implant versus the comparison patients. There were no apparent differences between the implant and comparison patients with respect to breast cancer (9.6 percent positive history among the total study population, $\mathrm{OR}=0.95 ; 95$ percent CI, 0.8 to 1.1 ) or systemic lupus erythematosus (1.8 percent, OR $=1.0$; 95 percent CI, 0.71.5). However, implant patients reported a positive family history of rheumatoid arthritis somewhat more often than comparison patients $(8.3$ percent positive history, $\mathrm{OR}=1.3$; 95 percent CI, 1.1 to 1.6$)$.

Attempts were made through logistic regression modeling to assess the independence of the various identified correlates of breast implant surgery. Although the individual estimates of risk changed somewhat, none of the previously identified correlates changed substantially as a result of adjustment for other factors. Thus, the strongest correlates of breast implants were age of surgery, calendar year of surgery, education, age at first birth, mammographic history, and body mass.

A final comparison assessed the influence of these major correlates of breast implants by specific categories of other types of plastic surgery (Table VI). Implant patients differed significantly from the patients with "other facial surgery" (mainly rhinoplasties) with respect to parity (implant patients had their first child at earlier ages and were less likely to be nulliparous) and mammographic screening history (more often screened). Implant patients weighed significantly less than abdominoplasty or liposuction patients but were more similar than the other categories of plastic surgery with respect to reproductive history.

\section{DiscusSION}

Similar to several previous analyses, ${ }^{1,5}$ we found a number of differences between breast implant patients and women without such operations. However, in contrast to prior analyses that compared implant patients with women in the general population, we used as a comparison group women who had sought other types of plastic surgery at the same practices as the breast implant patients. Although this use of a more focused comparison group eliminated some of the differences previously observed, a 
Vol. 105, No. 3 / COMPARISON OF WOMEN BY TYPE OF PLASTIC SURGERY

TABLE III

Comparison of Breast Implant Patients and Other Plastic Surgery Patients on Menstrual, Reproductive, and Hormonal Characteristics

\begin{tabular}{|c|c|c|c|c|}
\hline Parameter & $\begin{array}{l}\% \text { of Breast Implant } \\
\text { Patients }(n=7447)\end{array}$ & $\begin{array}{l}\% \text { of Other Plastic } \\
\text { Surgery Patients } \\
(n=2203)\end{array}$ & $\begin{array}{l}\text { Adjusted } \\
\text { Odds Ratio* }\end{array}$ & $\begin{array}{c}95 \% \\
\text { Confidence } \\
\text { Interval }\end{array}$ \\
\hline \multicolumn{5}{|c|}{ Age at menarche (years) } \\
\hline 11 or younger & $15.6 \dagger$ & $18.4 \dagger$ & 1.00 & \\
\hline 12 & 23.6 & 23.7 & 1.13 & $0.9-1.3$ \\
\hline 13 & 27.5 & 27.5 & 1.13 & $0.9-1.3$ \\
\hline 14 & 12.9 & 11.6 & 1.18 & $0.9-1.4$ \\
\hline 15 or greater & 10.6 & 7.8 & 1.41 & $1.1-1.7$ \\
\hline Unknown & 9.7 & 10.9 & 0.98 & $0.8-1.2$ \\
\hline \multicolumn{5}{|c|}{ Number of pregnancies } \\
\hline 0 & 10.6 & 17.0 & 1.00 & \\
\hline 1 & 13.8 & 14.8 & 1.47 & $1.2-1.8$ \\
\hline 2 & 28.0 & 25.5 & 1.84 & $1.5-2.2$ \\
\hline 3 & 22.5 & 21.0 & 1.74 & $1.4-2.1$ \\
\hline $4+$ & 24.5 & 20.3 & 1.82 & $1.5-2.2$ \\
\hline Unknown & 0.6 & 1.5 & 0.56 & $0.3-1.0$ \\
\hline \multicolumn{5}{|c|}{ Age at first birth (years) } \\
\hline$<20$ & 18.4 & 10.6 & 1.00 & \\
\hline $20-24$ & 30.6 & 27.7 & 0.64 & $0.5-0.8$ \\
\hline $25-29$ & 17.5 & 16.2 & 0.64 & $0.5-0.8$ \\
\hline $30+$ & 10.0 & 13.0 & 0.46 & $0.4-0.6$ \\
\hline Nulliparous & 16.1 & 24.2 & 0.39 & $0.3-0.5$ \\
\hline Unknown & 7.4 & 8.2 & 0.55 & $0.4-0.7$ \\
\hline \multicolumn{5}{|c|}{ Used oral contraceptives } \\
\hline No & 22.5 & 25.2 & 1.00 & \\
\hline Yes & 68.8 & 65.5 & 1.53 & $1.3-1.7$ \\
\hline Unknown & 8.6 & 9.3 & 1.25 & $1.0-1.5$ \\
\hline \multicolumn{5}{|c|}{ Used female hormones } \\
\hline No & 47.0 & 50.4 & 1.00 & \\
\hline Yes & 45.2 & 40.9 & 1.18 & $1.0-1.3$ \\
\hline Unknown & 7.9 & 8.6 & 0.97 & $0.8-1.2$ \\
\hline
\end{tabular}

* Adjusted for age at and year of initial plastic surgery.

$\dagger$ Age-adjusted frequencies.

number of distinctive characteristics of breast implant patients persisted.

In both of the previous studies that have examined characteristics of breast implant patients, ${ }^{1,5}$ a number of differences were apparent between the implant patients and women in the general population. Similar to these other investigations, we found that patients with implants weighed significantly less, had earlier ages at their first pregnancy or birth, and were more often oral contraceptive users. However, our results did not support the observations of others that implant patients more often tend to be regular consumers of alcoholic beverages.

Cook and others ${ }^{1}$ observed that patients with breast implants had more induced abortions, were more likely to dye their hair, and had more sexual partners than comparison patients. We did not collect such information and, therefore, were unable to assess these relationships. However, the findings from our study and theirs were comparable in not showing differences between breast implant pa- tients and others with respect to number of pregnancies (after adjustment for age at first birth), history of cigarette smoking, or past medical conditions.

Whether breast implants can cause adverse health effects is an issue of great scientific and public interest. ${ }^{6}$ However, to distinguish whether adverse health effects are a direct consequence of exposure to silicone, it is important to consider other disease correlates. It is with this in mind that we, as well as others, collected information on other characteristics that could contribute to risk for a variety of diseases. The purpose of our analyses was to evaluate variables for consideration as confounding variables in disentangling effects of breast implants from those of other risk factors.

It has been postulated that silicone breast implants may contribute to a variety of diseases, including cancer and some connective tissue diseases, in particular, systemic sclerosis, rheumatoid arthritis, systemic lupus erythematosus, and an entity termed "human adjuvant 
TABLE IV

Comparison of Breast Implant Patients and Other Plastic Surgery Patients on Various Health Parameters

\begin{tabular}{|c|c|c|c|c|}
\hline Parameter & $\begin{array}{l}\% \text { of Breast Implant } \\
\text { Patients }(n=7447)\end{array}$ & $\begin{array}{c}\% \text { of Other Plastic } \\
\text { Surgery Patients } \\
(n=2203)\end{array}$ & $\begin{array}{l}\text { Adjusted } \\
\text { Odds Ratio* }\end{array}$ & $\begin{array}{l}\text { 95\% Confidence } \\
\text { Interval }\end{array}$ \\
\hline \multicolumn{5}{|l|}{ Previous breast biopsy } \\
\hline No & $72.7 \dagger$ & $73.1 \dagger$ & 1.00 & \\
\hline Yes & 26.3 & 25.6 & 1.06 & $0.9-1.2$ \\
\hline Unknown & 1.0 & 1.2 & 0.80 & $0.5-1.3$ \\
\hline \multicolumn{5}{|l|}{ Previous hysterectomy } \\
\hline No & 56.5 & 59.0 & 1.00 & \\
\hline Yes & 33.4 & 30.1 & 1.14 & $1.0-1.3$ \\
\hline Unknown & 10.1 & 10.9 & 0.94 & $0.8-1.1$ \\
\hline \multicolumn{5}{|c|}{$\begin{array}{l}\text { Previous surgery involving removal of } \\
\text { ovary(ies) }\end{array}$} \\
\hline No & 68.6 & 68.8 & 1.00 & \\
\hline One ovary & 7.2 & 6.9 & 1.04 & $0.8-1.3$ \\
\hline Both ovaries & 14.4 & 13.7 & 1.01 & $0.9-1.2$ \\
\hline Unknown & 9.7 & 10.6 & 0.91 & $0.8-1.1$ \\
\hline \multicolumn{5}{|c|}{ Perform breast self-examinations } \\
\hline No & 14.7 & 16.0 & 1.00 & \\
\hline Yes & 76.3 & 73.7 & 1.17 & $1.0-1.4$ \\
\hline Unknown & 9.0 & 10.3 & 0.97 & $0.8-1.2$ \\
\hline \multicolumn{5}{|l|}{ Had a mammogram } \\
\hline No & 18.2 & 27.5 & 1.00 & \\
\hline Yes & 81.6 & 72.1 & 2.14 & $1.8-2.5$ \\
\hline Unknown & 0.2 & 0.4 & 0.75 & $0.3-1.9$ \\
\hline \multicolumn{5}{|c|}{ Number of Pap smears in past 5 years } \\
\hline 0 & 7.3 & 8.9 & 1.00 & \\
\hline 1 & 5.4 & 4.0 & 1.38 & $1.0-1.9$ \\
\hline $2-4$ & 25.9 & 23.4 & 1.18 & $0.9-1.5$ \\
\hline $5+$ & 52.2 & 53.5 & 1.05 & $0.8-1.3$ \\
\hline Unknown & 9.3 & 10.1 & 0.96 & $0.7-1.2$ \\
\hline
\end{tabular}

* Adjusted for age at and year of initial plastic surgery.

$\dagger$ Age-adjusted frequencies.

disease." ${ }^{6}$ These diseases, probably because of their rarity, have received only limited epidemiologic attention. Thus, there are few identified risk factors to consider as potential confounders in evaluating the independent effects of silicone exposure. Apart from some reported relationships with age and race, few factors have been identified. Several studies have reported a reduced risk of rheumatoid arthritis among oral contraceptives users, ${ }^{7-10}$ although the issue is far from resolved. ${ }^{11}$ Furthermore, some studies have shown that hair dyes $^{12}$ or hair straighteners ${ }^{13}$ increase the risk of systemic lupus erythematosus or systemic scleroderma. Genetic factors have also been implicated in both the cause of systemic lupus erythematosus ${ }^{14}$ and rheumatoid arthritis, ${ }^{15}$ although reporting bias may have been involved. ${ }^{16}$ In our study, we collected data on some of these proposed risk factors for connective tissue disease but not on others (e.g., hair dye use). It is noteworthy that we did not observe differences between the two groups of patients with respect to most familial diseases. However, implant patients significantly more often reported prior usage of oral contraceptives and familial histories of rheumatoid arthritis, factors that will need to be taken into account in future analyses of the risk of rheumatoid arthritis among our implant patients.

The relationship of breast implants to cancer risk remains unresolved. ${ }^{17}$ The site that has received the most attention has been breast cancer. ${ }^{18-23}$ Despite studies that have shown that breast implants can deter mammographic visualization of breast lesions, ${ }^{24,25}$ most epidemiologic studies that have considered the longterm effects of silicone breast implants have actually observed decreases in breast cancer risk, with several of the studies showing significant reductions. This finding has led some investigators to postulate that implants may in fact be biologically advantageous, ${ }^{5,19}$ either through a compressive effect of the implants on surrounding breast tissue, interference with blood supply, or a beneficial immunologic response. However, because breast implant patients have been shown to differ from both the general population and other plastic surgery patients on a number of important breast can- 
TABLE V

Comparison of Breast Implant Patients and Other Plastic Surgery Patients on Various Factors

\begin{tabular}{|c|c|c|c|c|}
\hline Parameter & $\begin{array}{l}\% \text { of Breast Implant } \\
\text { Patients }(n=7447)\end{array}$ & $\begin{array}{c}\% \text { of Other Plastic } \\
\text { Surgery Patients } \\
(n=2203)\end{array}$ & $\begin{array}{c}\text { Adjusted } \\
\text { Odds Ratio* }\end{array}$ & $\begin{array}{l}\text { 95\% Confidence } \\
\text { Interval }\end{array}$ \\
\hline \multicolumn{5}{|l|}{ Current weight $(\mathrm{kg})$} \\
\hline$<56$ & $31.9 \dagger$ & $27.0+$ & 1.00 & \\
\hline $56-61$ & 28.9 & 26.8 & 0.89 & $0.8-1.0$ \\
\hline $62-67$ & 17.5 & 18.1 & 0.79 & $0.7-0.9$ \\
\hline $68+$ & 20.7 & 26.7 & 0.63 & $0.5-0.7$ \\
\hline Unknown & 1.0 & 1.4 & 0.55 & $0.3-0.9$ \\
\hline \multicolumn{5}{|l|}{ Height $(\mathrm{cm})$} \\
\hline$<160$ & 16.6 & 21.1 & 1.00 & \\
\hline $160-164$ & 26.4 & 29.3 & 1.12 & $0.9-1.3$ \\
\hline $165-169$ & 29.6 & 25.5 & 1.35 & $1.2-1.6$ \\
\hline $170+$ & 26.9 & 23.2 & 1.42 & $1.2-1.7$ \\
\hline Unknown & 0.5 & 1.0 & 0.64 & $0.4-1.2$ \\
\hline \multicolumn{5}{|c|}{ Body mass index (wt in $\mathrm{kg} / \mathrm{ht}$ in $\mathrm{m}^{2}$ ) } \\
\hline$<20.5$ & 30.6 & 22.4 & 1.00 & \\
\hline $20.5-22.4$ & 30.2 & 28.4 & 0.78 & $0.7-0.9$ \\
\hline $22.5-24.4$ & 18.5 & 19.0 & 0.67 & $0.6-0.8$ \\
\hline $24.5+$ & 19.7 & 28.7 & 0.48 & $0.4-0.6$ \\
\hline Unknown & 1.0 & 1.5 & 0.43 & $0.3-0.7$ \\
\hline \multicolumn{5}{|c|}{ Drink alcohol once a month or more } \\
\hline No & 22.4 & 21.4 & 1.00 & \\
\hline Yes & 68.1 & 68.6 & 0.93 & $0.8-1.0$ \\
\hline Unknown & 9.5 & 10.0 & 0.88 & $0.7-1.1$ \\
\hline \multicolumn{5}{|l|}{ Ever smoke cigarettes } \\
\hline No & 45.7 & 47.1 & 1.00 & \\
\hline Yes & 45.1 & 43.0 & 1.04 & $0.9-1.2$ \\
\hline Unknown & 9.2 & 9.9 & 0.93 & $0.8-1.1$ \\
\hline
\end{tabular}

* Adjusted for age at and year of initial plastic surgery.

$\dagger$ Age-adjusted frequencies.

cer predictors, we cannot too readily discount the influence of these differences, as discussed elsewhere. ${ }^{22}$ The tendency for breast implant patients to have small breasts has been suggested as one such possible explanatory factor, although the relationship of breast size to subsequent breast cancer risk remains to be clarified.

Another notable characteristic of breast implant patients is their earlier ages at first births, age at first birth being an established breast cancer risk factor. ${ }^{26}$ This characteristic, in fact, could have a substantial impact, given that women with first births after the age of 30 have breast cancer risks 2 to 3 times that of those with births before the age of 20. The other characteristic of importance in the evaluation of breast cancer risk is body size. Relationships with breast cancer are somewhat complex; although obesity is actually an established risk factor for postmenopausal onset disease, it actually operates in an opposite manner for premenopausal disease, with obese women being at low risk. ${ }^{27}$ Thus, the finding that women with breast implants tend to be thin could not explain their lower risks of premenopausal onset breast cancer but could contribute to observed breast cancer risks at older ages. In future studies that evaluate breast cancer risk among patients with breast implants, it will, therefore, be important to consider carefully effects of body size according to ages at which the disease developed.

In terms of other cancers, only a few studies have evaluated risks in any detail. ${ }^{22,28}$ One of these studies ${ }^{28}$ found that breast implant patients had significant excesses of both lung and vulvar cancer, as well as a not significant elevation of cervical cancer. Because cigarette smoking has been related to risk of all three of these cancers, ${ }^{17}$ it has been postulated that such elevations might be attributable to this lifestyle characteristic. ${ }^{28}$ It was of note that we did not find breast implant patients to differ substantially from other plastic surgery patients on this lifestyle factor. This would lessen the probability that any observed differences in risk of these diseases between our patients might be attributable solely to this factor. Nonetheless, investigators need to pay some attention to other lifestyle factors, including number of sexual partners, an established risk factor for both cervical and vulvar cancers. ${ }^{29,30}$

In summary, our study shows that a popula- 
TABLE VI

Adjusted Odds Ratios* for Major Predictors of Breast Implants Compared with Specific Categories of Other Types of Plastic Surgery

\begin{tabular}{|c|c|c|c|c|}
\hline Parameter & $\begin{array}{l}\text { Abdominoplasty/ } \\
\text { Liposuction } \\
(n=482)\end{array}$ & $\begin{array}{l}\text { Blepharoplasty/ } \\
\text { Rhytidectomy } \\
(n=773)\end{array}$ & $\begin{array}{l}\text { Other Facial } \\
\quad(n=556)\end{array}$ & $\begin{array}{c}\text { Other Surgeries } \\
\quad(n=392)\end{array}$ \\
\hline \multicolumn{5}{|l|}{ Education } \\
\hline High school or less & 1.00 & 1.00 & 1.00 & 1.00 \\
\hline Some college & $0.77 \dagger$ & $0.60 \dagger$ & $0.68 \dagger$ & 0.98 \\
\hline College or greater & $0.50 \dagger$ & $0.44 \dagger$ & $0.50 \dagger$ & $0.56 \dagger$ \\
\hline Unknown & 0.71 & 0.87 & 0.57 & $0.24 \dagger$ \\
\hline \multicolumn{5}{|l|}{ Age at first birth (years) } \\
\hline$<20$ & 1.00 & 1.00 & 1.00 & 1.00 \\
\hline $20-24$ & 0.87 & $0.69 \dagger$ & $0.64 \dagger$ & 0.74 \\
\hline $25-29$ & 1.09 & $0.66 \dagger$ & $0.64 \dagger$ & 0.84 \\
\hline $30+$ & 0.95 & $0.49 \dagger$ & $0.39 \dagger$ & 0.71 \\
\hline Nulliparous & $0.69 \dagger$ & $0.51 \dagger$ & $0.33 \dagger$ & $0.62 \dagger$ \\
\hline Unknown & 0.75 & 0.68 & $0.57 \dagger$ & $0.60 \dagger$ \\
\hline \multicolumn{5}{|l|}{ Current weight (kg) } \\
\hline$<56$ & 1.00 & 1.00 & 1.00 & 1.00 \\
\hline $56-61$ & $0.46 \dagger$ & 0.97 & 0.95 & 0.87 \\
\hline $62-67$ & $0.38 \dagger$ & 0.90 & 1.03 & $0.71 \dagger$ \\
\hline $68+$ & $0.23 \dagger$ & 0.88 & 0.89 & $0.50 \dagger$ \\
\hline Unknown & $0.24 \dagger$ & 1.08 & 0.58 & 0.74 \\
\hline \multicolumn{5}{|l|}{ Had a mammogram } \\
\hline No & 1.00 & 1.00 & 1.00 & 1.00 \\
\hline Yes & 1.34 & 1.16 & $2.26 \dagger$ & $2.14 \dagger$ \\
\hline Unknown & 1.60 & 0.79 & 0.57 & 3.59 \\
\hline
\end{tabular}

* Adjusted for age at and year of initial surgery. Odds ratios compare the distribution of characteristics in the implant patients to characteristics for patients defined by their specific type of plastic surgery. For instance, an odds ratio of 2.0 indicates that a characteristic has twice the odds of occurrence among breast implant patients compared with patients with other types of plastic surgery, whereas an odds ratio of 0.5 indicates that the breast implant patients have half the odds.

$\dagger$ The 95 percent confidence interval for the odds ratio excluded 1.0.

tion of women having other types of plastic surgery constitute a more comparable control group for breast implant patients than do women from the general population. However, there continue to be some different characteristics demonstrated among breast implant patients, including their tending to be thin, have their children at early ages, and be regularly screened for breast disease. Thus, a complete assessment of the health effects of silicone breast implants needs to take into account the influence of several potential disease confounders that, independent of silicone exposure, could affect health status.

\section{Louise A. Brinton, Ph.D. \\ Environmental Epidemiology Branch \\ National Cancer Institute \\ Executive Plaza South, Room 7068 \\ 6120 Executive Boulevard, MSC 7234 \\ Bethesda, Md. 20892-7234 \\ brinton@nih.gov \\ REFERENCES}

1. Cook, L. S., Daling, J. R., Voigt, L. F., et al. Characteristics of women with and without breast augmentation. J.A.M.A. 277: 1612, 1997.

2. Stewart, M. W., and Elliott, M. Characteristics of women with and without breast implants. J.A.M.A. 278: 818, 1997.
3. Brinton, L. A., Toniolo, P., and Pasternack, B. S. Epidemiologic follow-up studies of breast augmentation patients. J. Clin. Epidemiol. 48: 557, 1995.

4. Breslow, N. E., and Day, N. E. Statistical Methods in Cancer Research, Vol. 1. The Analysis of Case Control Studies. Lyon, France: International Agency for Research on Cancer, 1980.

5. Brinton, L. A., Malone, K. E., Coates, R. J., et al. Breast enlargement and reduction: Results from a breast cancer case-control study. Plast. Reconstr. Surg. 97: 269, 1996.

6. Silverman, B. G., Brown, S. L., Bright, R. A., et al. Reported complications of silicone gel breast implants: An epidemiologic review. Ann. Intern. Med. 124: 744, 1996.

7. Hazes, J. M., and van Zeben, D. Oral contraception and its possible protection against rheumatoid arthritis. Ann. Rheum. Dis. 50: 72, 1991.

8. Koepsell, T., Dugowson, C., Voigt, L., et al. Preliminary findings from a case-control study of the risk of rheumatoid arthritis in relation to oral contraceptive use. Br. J. Rheumatol. 28 (Suppl. 1): 41, 1989.

9. Spector, T. D., Roman, E., and Silman, A. J. The pill, parity, and rheumatoid arthritis. Arthritis Rheum. 33: 782, 1990.

10. Vandenbroucke, J. P., Valkenburg, H. A., Boersma, J. W., et al. Oral contraceptives and rheumatoid arthritis: Further evidence for a preventive effect. Lancet 2: 839, 1982.

11. Pladevall-Vila, M., Delclos, G. L., Varas, C., et al. Controversy of oral contraceptives and risk of rheumatoid arthritis: Meta-analysis of conflicting studies and re- 
view of conflicting meta-analyses with special emphasis on analysis of heterogeneity. Am. J. Epidemiol. 144: 1, 1996.

12. Freni-Titulaer, L. W. J., Kelley, D. B., Grow, A. G., et al. Connective tissue disease in southeastern Georgia: A case-control study of etiologic factors. Am. J. Epidemiol. 130: 404, 1989.

13. Petri, M., and Allbritton, J. Hair product use in systemic lupus erythematosus: A case-control study. Arthritis Rheum. 35: 625, 1992.

14. Tsao, B. P., and Wallace, D. J. Genetics of systemic lupus erythematosus. Curr. Opin. Rheumatol. 9: 377, 1997.

15. Lynn, A. H., Kwoh, C. K., Venglish, C. M., et al. Genetic epidemiology of rheumatoid arthritis. Am. J. Hum. Genet. 57: 150, 1995.

16. Kwoh, C. K., Venglish, C., Lynn, A. H., et al. Age, sex, and the familial risk of rheumatoid arthritis. Am. J. Epidemiol. 144: 15, 1996.

17. Brinton, L. A., and Brown, S. L. Breast implants and cancer. J. Natl. Cancer Inst. 89: 1341, 1997.

18. Berkel, H., Birdsell, D. C., and Jenkins, H. Breast augmentation: A risk factor for breast cancer? N. Engl. J. Med. 326: 1649, 1992.

19. Deapen, D. M., Bernstein, L., and Brody, G. S. Are breast implants anticarcinogenic? A 14-year follow-up of the Los Angeles Study. Plast. Reconstr. Surg. 99: 1346, 1997.

20. Friis, S., McLaughlin, J. K., Mellemkjaer, L., et al. Breast implants and cancer risk in Denmark. Int. J. Cancer 71: 956, 1997.

21. Glasser, J. W., Lee, N. C., and Wingo, P. A. Does Breast Augmentation Increase the Risk of Breast Cancer? In Proceedings of the Epidemic Intelligence Service 38th
Annual Conference, Atlanta Centers for Disease Control, Atlanta, Ga., April 3-7, 1989.

22. McLaughlin, J. K., Nyren, O., Blot, W. J., et al. Cancer risk among women with cosmetic breast implants: A population-based cohort study in Sweden. J. Natl. Cancer Inst. 90: 156, 1998.

23. Malone, K. E., Stanford, J. L., Daling, J. R., et al. Implants and breast cancer (Letter). Lancet 339: 1365, 1992.

24. Fajardo, L. L., Harvey, J. A., McAleese, K. A., et al. Breast cancer diagnosis in women with subglandular silicone gel-filled augmentation implants. Radiology 194: 859, 1995.

25. Handel, N., Silverstein, M. J., Gamagami, P., et al. Factors affecting mammographic visualization of the breast augmentation mammaplasty. J.A.M.A. 268: 1913, 1992.

26. Kelsey, J. L., Gammon, M. D., and John, E. M. Reproductive factors and breast cancer. Epidemiol. Rev. 15: 36, 1993.

27. Hunter, D. J., and Willett, W. C. Diet, body size, and breast cancer. Epidemiol. Rev. 15: 110, 1993.

28. Deapen, D. M., and Brody, G. S. Augmentation mammaplasty and breast cancer: A 5-year update of the Los Angeles Study. Plast. Reconstr. Surg. 89: 660, 1992.

29. Brinton, L. A., Nasca, P. C., Mallin, K., et al. Case-control study of cancer of the vulva. Obstet. Gynecol. 75: 859, 1990.

30. Herrero, R., Brinton, L. A., Reeves, W. C., et al. Sexual behavior, venereal diseases, hygiene practices, and invasive cervical cancer in a high-risk population. Cancer 65: 380, 1990. 